\title{
Kaura-rehuvirnasäilörehu teurashiehojen ruokinnassa
}

\author{
Merja Manninen ${ }^{1)}$, Pentti Ojajärvi²) ja Marjatta Suvitie ${ }^{3)}$ \\ ${ }^{1)}$ MTT, 31600 Jokioinen, merja.manninen@mtt.fi \\ 2)Pohjois-Karjalan ammattikorkeakoulu,82430Puhos, pentti.ojajarvi@pkky.fi \\ ${ }^{3)}$ MTT, 71750 Maaninka, marjatta.suvitie@mtt.fi
}

\begin{abstract}
Johdanto
Virnoja viljellään seoksena viljojen kanssa, koska virna typpeä sitovana palkokasvina vähentää kasvuston typpilannoitustarvetta ja lisää siten säilörehun raakavalkuaispitoisuutta (Lehto \& Joki-Tokola 1999a, Joki-Tokola ym. 2002). Rehuvirnan (Vicia sativa L.) viljely on yleistä luonnonmukaisessa tuotannossa ja sen käyttö on lisääntynyt luonnonmukaisen tuotannon lisääntyessä (Leinonen \& Nykänen 2001). Seosviljelystä on etua luonnonmukaisessa tuotannossa, jossa typpi usein muodostuu satoa rajoittavaksi tekijäksi. Seoskasvustosta voidaan korjata kesän aikana kaksi säilörehusatoa, jolloin rehun raakavalkuaispitoisuus ja sulavuus lisääntyvät yhteen korjuukertaan verrattuna. Yhden korjuukerran etuna on kuitenkin suurempi sato samoin kuin korjuukustannusten väheneminen. Seoskasvuston yhdestä korjuukerrasta on uudelle nurmelle myös vähemmän haittaa kuin kahdesta korjuukerrasta. Virnan viljely seoksena kauran kanssa on yleistä sekä viherlannoitus- että rehukäytössä (Lehto \& JokiTokola 1999b). Kaura soveltuu seoskasviksi hyvin kasvurytminsä ja kortensa puolesta, mutta ongelmana on sen alhainen sulavuus. Kauraa paremmin seoskasvustoon voisi soveltua ohra, joka kuitenkin voi varjostaa virnaa huomattavasti. Hereford-sonneilla tehdyssä kokeessa rehuvirna paransi hieman kokoviljasäilörehun tuotantovaikutuksia (Joki-Tokola ym. 2002).

Teurashiehojen ruokintaa on maassamme tutkittu 1990-luvun puolivälin jälkeen neljässä kokeessa (Rinne ym. 1998, Rinne ja Ojajärvi 1998, Manninen ja Ojajärvi 2000, Manninen ym.2002). Lypsylehmien ja sitä kautta välitykseen menevien vasikoiden määrän vähentyessä kaikki käytettävissä olevat naudanlihan tuotantomahdollisuudet tulee hyödyntää tehokkaasti. Tämä tutkimus selvitti luomukasvustosta valmistetun kaura-rehuvirnaseossäilörehun tuotantovaikutukset hf-hiehoilla, kun vertailurehuna oli tavanomaisella tuotantotavalla heinän odelmasta valmistettu nurmisäilörehu. Hiehot ruokittiin vapaasti mainituilla säilörehuilla ja teurastettiin 13 kk:n iässä.
\end{abstract}

\section{Aineisto ja menetelmät}

\section{Eläinaines ja tuotanto-olosuhteet}

Kokeeseen otettiin 20 11.3.-9.4.2000 MTT:n emolehmänavetalla syntynyttä hf-lehmävasikkaa. Vasikoiden isinä olivat hf-sonnit Teristen Jesse (10) ja Thorsvik Kentauri (10). Ennen koetta vasikat olivat emiensä kanssa laitumella eivätkä saaneet siellä väkirehua. Vasikat vieroitettiin 6.9.2000 221 kilon ja 160 päivän iässä, johon mennessä ne olivat kasvaneet keskimäärin $1108 \mathrm{~g} / \mathrm{d}$. Kokeen alkaessa 13.10.2000 vasikat olivat keskimäärin 196 päivän ikäisiä ja painoivat $235 \mathrm{~kg}$. Koe tehtiin Kiteen oppimiskeskuksen navetassa, jossa on yksilöruokintaparret. Eläimet punnittiin ja kuntoluokitettiin (Lowman ym. 1976) säännöllisesti.

\section{Rehut ja ruokinta}

Rehuina olivat luomukasvustosta tehty kaura-rehuvirnasäilörehu (KVSR) ja tavanomaisesti viljellystä kasvustosta valmistettu nurmisäilörehu (NSR). Tavoitteena oli, että karkearehujen D-arvo olisi alle 65\%. Kaura-rehuvirnasäilörehu valmistettiin seoskasvustosta Aarre-kauran ja Ebena-rehuvirnan siementen kylvömäärien ollessa 94 ja $55 \mathrm{~kg} / \mathrm{ha}$. Lannoitukseen käytettiin naudan kuivikelantaa $14 \mathrm{t} / \mathrm{ha}$, mangaanilannosta (Mn 5 \%) 200 ja sinkkilannosta (Zn $3 \%) 120 \mathrm{~kg} / \mathrm{ha}$ maalajin ollessa multava hieno hieta. Rehu korjattiin 11.-14.8.2000 kaksoissilppurilla torniin (50 t) ja laakasiiloon (12 t). Säilöntään käytettiin AIV 2 Plus -liuosta (760 g muurahaishappoa $/ \mathrm{kg}$ ja $55 \mathrm{~g}$ ammoniumformiaatti $/ \mathrm{kg}$ ) 5,5 1/t. Esikuivattu nurmisäilörehu kaadettiin heinän odelmasta 22.-24.8.2000 (timotei-nurminata-apila kasvusto 70-25-5\%) niittomurskaimella ja paalattiin silppuavalla pyöröpaalaimella noin $700 \mathrm{~kg}: \mathrm{n}$ pyöröpaaleihin, jotka käärittiin kuudesti. Säilöntään käytettiin AIV 2 Plus -liuosta 5 1/t. Syötetyt rehut analysoitiin Valio Oy:n Lapinlahden aluelaboratoriossa NIR-tekniikalla (Nousiainen ja Hellämäki 1999). Säilörehun D-arvo määritettiin myös NIR-tekniikalla (Hellämäki 2001) Friedelin (1990) esittämään sellulaasisulavuuteen perustuen. Rehuille laskettiin syönti-indeksi (Nousiainen ja Huhtanen 
2000). Hiehot saivat säilörehua vapaasti. Kokeen kolmen ensimmäisen kuukauden ajan hiehot ruokittiin kerran päivässä aamulla, sen jälkeen kahdesti päivässä. Kivennäisenä käytettiin Seleeni HerttaMinera Muroa (Suomen Rehu Oy; Ca 200, P 50, Na 70 ja Mg 70 g/kg) ja vitamiinina ADEvitamiiniseosta (Suomen Rehu Oy; A $2000000 \mathrm{ky} / \mathrm{kg}, D_{3} 400000 \mathrm{ky} / \mathrm{kg}$, E $1000 \mathrm{mg} / \mathrm{kg}$, Se 20 $\mathrm{mg} / \mathrm{kg}$ ). Vettä eläimet saivat vapaasti.

\section{Teurastus, ruhon ja lihan laatu}

Hiehot teurastettiin Kiteen opetusteurastamossa 13 kk:n iässä. Ruhot luokitettiin EUROP-luokituksen mukaisesti. Ulkofileestä määritettiin loppu-pH 36-48 h teurastuksesta ja leikattiin pala, joka toimitettiin LTK:een aistinvaraiseen arvosteluun ja konsistenssimääritykseen. Näytettä raakakypsytettiin $14 \mathrm{~d}$ $+2 \pm 1^{\circ} \mathrm{C}$ ennen pakastusta.

\section{Tilastollinen käsittely}

Tilastollinen analysointi suoritettiin käyttäen Wilcoxonin testiä (Wilcoxon Signed-rank Test) ja yhden otoksen merkkitestiä (The Sign Test). Molemmat testit kuuluvat parametrittomiin menetelmiin. Wilcoxonin testiä käytettiin jatkuvien muuttujien ja merkkitestiä järjestysasteikollisten, mutta ei jatkuvien muuttujien tilastollisessa analysoinnissa. Käsittelyjen erolle laskettiin likimääräiset 95 \% luottamusvälit kuvaamaan havaitun keskimääräisen eron tarkkuutta. Analysointi suoritettiin SAS-ohjelmiston Univariate-proseduurilla (SAS 1999). Luottamusvälien ja Wilcoxonin testin yhteydessä erotuksen eli Hodgesin-Lehmanin estimaatin laskemiseksi tehtiin oma SAS-ohjelma käyttäen laskukaavoja, jotka ovat esittäneet mm. Gibbons ja Chakraborti (1992).

\section{Tulokset ja tulosten tarkastelu}

KVSR:n raaka-aineiden ja rehuraaka-aineen koostumus ennen korjuuta esitetään Taulukossa 1. Kaurarehuvirnan tuoresadoksi määritettiin $62000 \mathrm{~kg} / \mathrm{ha}$ ja kuiva-ainesadoksi $8060 \mathrm{~kg} / \mathrm{ha}$. Rehuvirnan osuus kasvustosta oli ennen korjuuta $85 \%$ ja kauran $15 \%$, josta röyhyjä $1 / 3$ ja olkea $2 / 3$. Korjuuhetkellä kasvusto oli melko märkää, rehuvirnan kuiva-aine oli $12,7 \%$ ja kauran 14,7 \%.Kasvukauden loppuvaiheessa rehevä rehuvirnakasvusto osin tukahdutti kaurakasvustoa aiheuttaen kauran osittaista pilaantumista rehuvirnan alla. Kyseisen kesän kasvuolosuhteissa virnan siemenmääräksi kylvettäessä olisikin riittänyt $30 \mathrm{~kg} / \mathrm{ha}$.

Syötetyn KVSR:n KA-pitoisuus oli keskimäärin 257 ja NSR:n 296 g/kg, pH-arvot vastaavasti 3,84 ja 4,09. KVSR:n D-arvo oli keskimäärin 63,1\% ja KA-kilo sisälsi 473 g NDF-kuitua, 0,86 RY, $176 \mathrm{~g}$ raakavalkuaista, $80 \mathrm{~g}$ OIV ja $39 \mathrm{~g}$ PVT. NSR:n vastaavat arvot olivat 64,4\%, $524 \mathrm{~g}, 0,88 \mathrm{RY}$, 130 g, 78 g ja -3 g. KVSR:n syönti-indeksiksi saatiin 90 ja NSR:n 98. Säilönnällisen laadun arvosanaksi saatiin vastaavasti 8,5 ja 8,6 . Titrattua sokeria NSR sisälsi NIR-määrityksen mukaan riittävästi, KVSR liian vähän. Energian saannissa eläinten välille ei muodostunut eroja ollen keskimäärin 5,1 RY/d, mutta KVSR-ruokinnalla raakavalkuaisen saanti muodostui merkitsevästi suuremmaksi kuin NSR-ruokinnalla ( $<<0,001,1027$ vs. $763 \mathrm{~g} / \mathrm{d}$, Taulukko 2).

Koe kesti keskimäärin 199 d (Taulukko 3). Alkuperäisessä tutkimussuunnitelmassa hiehoille asetettiin $200 \mathrm{~kg}: n$ teuraspainotavoite. Koska hiehojen kasvu oli odotettua heikompaa muutettiin tutkimussuunnitelmaa siten, että kaikki hiehot teurastettiin kiinteässä 13 kk:n iässä. Toimenpiteellä pyrittiin vähentämään myös loppukeväällä pienten syöttöerien kyseessä ollessa rehujen lämpenemisestä aiheutuva syönnin väheneminen ja sitä kautta kasvun heikkeneminen.

Hiehojen kunto oli kokeen alkaessa keskimäärin 3,0 ja teurastettaessa 0,2 yksikköä heikompi. Kokeen päättyessä hiehojen elopaino oli keskimäärin $355 \mathrm{~kg}$ ja teuraspainoksi muodostui $170 \mathrm{~kg}$. Teuras-\% oli 48,0. Ruokinta ei vaikuttanut hiehojen kasvuun KVSR-hiehojen päiväkasvun ollessa 583 ja NSR-hiehojen 624 g/d. Keskimääräiseksi nettokasvuksi saatiin 265 g/d. Lisäkasvukiloa kohden hiehot söivät säilörehun KA:tta keskimäärin $10,1 \mathrm{~kg}$ ja nettokasvukiloa kohden 23,2 kg.. KVSR-hiehojen raakavalkuaisen saanti lisä- ja nettokasvukiloa kohden muodostui NSR-hiehoja suuremmaksi $(\mathrm{p}<0,001)$ johtuen luonnollisesti KVSR:n suuremmasta valkuaispitoisuudesta. Ruhot luokitettiin vähärasvaisiksi rasvaluokan ollessa keskimäärin 2,1 ja lihakkuuden keskimäärin 4,8.

Ruokinta ei vaikuttanut hiehojen ulkofileen aistinvaraiseen laatuun mureuden ollessa keskimäärin 4,3, mehukkuuden 4,3 ja maun 4,8, kun normaaliarvona pidetään arvoa 5 (Taulukko 4). KVSRruokinnalla olleiden hiehojen ulkofileen konsistenssi mitattiin suuntaa antavasti suuremmaksi kuin NSR-hiehojen ulkofileen konsistenssi ( $<<0,10,14,6$ vs. 12.2). Konsistenssiarvojen perusteella ulkofileet olivat sitkeitä. 
Taulukko 1. Kaura-rehuvirnasäilörehun raaka-aineiden koostumus.

\begin{tabular}{lrrrr}
\hline & $\begin{array}{l}\text { Proteiini } \\
\text { g/kg KA }\end{array}$ & $\begin{array}{r}\text { Tärkkelys } \\
\text { g/kg KA }\end{array}$ & $\begin{array}{r}\text { D-arvo } \\
\text { \% KA:ssa }\end{array}$ & $\begin{array}{r}\text { NDF } \\
\text { g/kg KA }\end{array}$ \\
\hline Rehuvirna 4.8. & 220,8 & 39,6 & 61,9 & 489 \\
Rehuvirna 10.8. & 236,9 & 80,5 & 64,8 & 419 \\
Kaura 4.8. & 143,9 & 46,4 & 54,5 & 657 \\
Kauran röyhy 10.8. & 202,6 & 122,3 & 69,5 & 547 \\
Kauran olki 10.8. & 97,3 & & 43,7 & 723 \\
Kaura-rehuvirna, raaka-aine 11.8. & 205,5 & 75,3 & 61,2 & 483 \\
\hline
\end{tabular}

Taulukko 2. Hiehojen syönti ja ravintoaineiden saanti.

\begin{tabular}{lcccc}
\hline Ruokinta & NSR & KVSR & $\begin{array}{c}\text { Erotuksen } \\
\text { luottamusväli (95\%) }\end{array}$ & $\begin{array}{r}\text { Tilastollinen } \\
\text { merkitsevyys }\end{array}$ \\
\hline $\begin{array}{l}\text { Eläinten lukumäärä } \\
\text { KA, kg }\end{array}$ & 10 & 10 & & \\
$\quad$ Nurmisäilörehu & 5,84 & & & \\
Kauravirnasäilörehu & & 5,86 & & \\
Kivennäinen & 0,143 & 0,143 & & $* * *$ \\
Yhteensä & 5,99 & 6,00 & $-0,324: 0,288$ & $* *$ \\
RY & 5,15 & 5,05 & $-0,153: 0,371$ & \\
Raakavalkuainen, g & 763 & 1027 & $-315,6:-213,8$ & \\
NDF, g & 3055 & 2772 & $133,3: 434,3$ & $* * *$ \\
OIV, g & 455 & 467 & $-36,4: 11,6$ & $-258,2:-228,2$ \\
PVT, g & -18 & 225 & & \\
\hline
\end{tabular}

${ }_{1}$ o $\mathrm{p}<0,10 ; * \mathrm{p}<0,05 ; * * \mathrm{p}<0,01 ; * * * \mathrm{p}<0,001$.

Taulukko 3. Ruokinnan vaikutus hiehojen kasvuun, teurastuloksiin ja rehun muuntosuhteeseen.

\begin{tabular}{|c|c|c|c|c|}
\hline Ruokinta & NSR & KVSR & $\begin{array}{c}\text { Erotuksen } \\
\text { luottamusväli }(95 \%) \\
\end{array}$ & $\begin{array}{r}\text { Tilastollinen } \\
\text { merkitsevyys } 1\end{array}$ \\
\hline \multicolumn{5}{|l|}{ Paino, $\mathrm{kg}$} \\
\hline Syntymäpaino & 43,3 & 43,7 & $-4,47: 3,57$ & \\
\hline Vieroituspaino & 222 & 220 & $-7,8: 11,6$ & \\
\hline Kokeen alussa & 235 & 235 & $-8,0: 8,4$ & \\
\hline Kokeen lopussa & 359 & 352 & $-10,6: 25,6$ & \\
\hline Teuraspaino & 172 & 169 & $-7,9: 12,6$ & \\
\hline \multicolumn{5}{|l|}{ Kuntoluokka, } \\
\hline Kokeen alussa & 3,00 & 3,00 & $-0,125: 0,000$ & \\
\hline Kokeen lopussa & 2,75 & 2,88 & $-0,250: 0,123$ & \\
\hline \multicolumn{5}{|l|}{$I k \ddot{a}, d$} \\
\hline Vieroitusikä & 160 & 159 & $-5,5: 8,7$ & \\
\hline Kokeen alussa & 196 & 195 & $-5,5: 8,7$ & \\
\hline Kokeen lopussa & 395 & 395 & $-1,7: 2,1$ & \\
\hline Kokeen kesto & 199 & 200 & $-9,2: 6,4$ & \\
\hline \multicolumn{5}{|l|}{$K a s v u, g / d$} \\
\hline Ennen vieroitusta & 1110 & 1106 & $-72,3: 80,5$ & \\
\hline Kokeen aikana & 624 & 583 & $-28,9: 109,8$ & \\
\hline Nettokasvu $^{2}$ & 271 & 259 & $-28,1: 53,5$ & \\
\hline Teuras- $\%$ & 47,8 & 48,1 & $-1,86: 1,11$ & \\
\hline Lihakkuus $^{3}$ & 5,0 & 4,5 & $-0,50: 1,00$ & \\
\hline Rasvaisuus ${ }^{4}$ & 2,0 & 2,1 & $-0,50: 0,00$ & \\
\hline \multicolumn{5}{|l|}{ Rehun muuntosuhde } \\
\hline KA kg/lisäkasvu-kg & 9,67 & 10,46 & $-1,861: 0,287$ & \\
\hline KA kg/nettokasvu-kg & 22,50 & 23,85 & $-4,677: 1,988$ & \\
\hline $\mathrm{RY} /$ lisäkasvu-kg & 8,32 & 8,78 & $-1,363: 0,446$ & \\
\hline $\mathrm{RY} /$ nettokasvu-kg & 19,37 & 20,03 & $-3,482: 2,166$ & \\
\hline NDF g/lisäkasvu-kg & 4935 & 4825 & $-402,3: 622,3$ & \\
\hline NDF g/nettokasvu-kg & 11483 & 11003 & $-1116,2: 2076,8$ & \\
\hline RV g/lisäkasvu-kg & 1232 & 1788 & $-722,9:-390,5$ & $* * *$ \\
\hline RV g/nettokasvu-kg & 2866 & 4079 & $-1730,6:-694,5$ & $* * *$ \\
\hline OIV g/lisäkasvu-kg & 734 & 813 & $-160,9: 3,4$ & o \\
\hline OIV g/nettokasvu-kg & 1709 & 1854 & $-401,8: 110,7$ & \\
\hline
\end{tabular}

${ }_{1}^{1}$ o $\mathrm{p}<0,10 ; * \mathrm{p}<0,05 ; * * \mathrm{p}<0,01 ; * * * \mathrm{p}<0,001$.

${ }^{2}$ Nettokasvua laskettaessa alkupainon teuras-\%:na käytetty 50 .

${ }^{3}$ EUROP-luokitus: $\mathrm{O}-=4, \mathrm{O}=5, \mathrm{O}+=6$.

${ }^{4}$ EUROP-luokitus: $2=$ vähäinen, $3=$ keskinkertainen. 
Taulukko 4. Ruokinnan vaikutus ulkofileen aistinvaraiseen laatuun.

\begin{tabular}{|c|c|c|c|c|}
\hline Ruokinta & NSR & KVSR & $\begin{array}{c}\text { Erotuksen } \\
\text { luottamusväli }(95 \%) \\
\end{array}$ & $\begin{array}{r}\text { Tilastollinen } \\
\text { merkitsevyys }{ }^{1}\end{array}$ \\
\hline $\begin{array}{l}\text { Näytteiden lukumäärä } \\
\text { Aistinvarainen arvio }^{2}\end{array}$ & 10 & 10 & & \\
\hline Mureus & 4,5 & 4,1 & $-0,20: 1,44$ & \\
\hline Mehukkuus & 4,3 & 4,3 & $-0,50: 0,60$ & \\
\hline Maku & 4,9 & 4,8 & $-0,50: 0,30$ & \\
\hline Konsistenssi $^{3}$ & 12,2 & 14,6 & $-6,22: 1,10$ & o \\
\hline Ulkofileen $\mathrm{pH}$ & 5,7 & 5,8 & $-0,18: 0,04$ & \\
\hline
\end{tabular}

\section{Johtopäätökset}

Kaura-rehuvirnaseoskasvustossa rehuvirna varjosti kasvukauden loppuvaiheessa huomattavasti kauraa. Luomukasvustosta valmistettu kaura-rehuvirnasäilörehu osoittautui kokeessa heinän odelmasta valmistetun nurmisäilörehun veroiseksi rehuksi lihahiehojen ruokinnassa. Hiehojen kasvu oli keskimäärin vain $603 \mathrm{~g}$ päivässä, mitä voidaan pitää teuraaksi kasvatettaville hiehoille heikkona. Uudistukseen kasvatettaville hiehoille saavutettu kasvu olisi ollut sopiva. Hiehojen kasvu parantui merkittävästi, kun rehut annosteltiin loppukasvatuskaudella kaksi kertaa päivässä. Teurastulosten perusteella hiehot olisi voitu kasvattaa kyseisillä rehuilla korkeampaan teuraspainoon rasvoittumatta, mutta kasvatuskausi olisi tällöin pidentynyt. Väkirehulisällä hiehot olisivat todennäköisesti saavuttaneet korkeamman teuraspainon $13 \mathrm{kk}: n$ ikään mennessä.

\section{Kiitokset}

Kiitokset MTT:n emolehmänavetan, Kiteen koulutilan navetan ja opetusteurastamon henkilökunnalle sujuvasta ja huolellisesta yhteistyöstä kokeen toteutuksessa.

\section{Kirjallisuus}

Friedel, K. 1990. Die Schätzung des energetischen Futterwertes von Grobfutter mit Hilfe einer Cellulasemethode.[The estimation of the energetic feeding value of roughages by means of a cellulase method]. Wissenschaftliche Zeitung Universitet Rostock, N-Reihe 39, 78-86.

Gibbons, J.D. \& Chakraborti, S. 1992. Nonparametric statistical inference. Third edition. New York: Marcel Dekker. ISBN 0-8247-8661-0. 462 p.

Hellämäki, M. 2001. Artturi-rehuanalyysi. NURMI 2001 Symposium: esitykset ja tilastokuvauksia. Suomen nurmiyhdistyksen julkaisu nro 15 , p. 68-71.

Joki-Tokola, E., Huuskonen, A., Huttu, S. \& Kiljala, J. 2002. Rehuvirna lihanautojen kokoviljasäilörehuruokinnassa. In: Maataloustieteen päivät 9.-10.1.2002. Kotieläintiede. MKL:n julkaisuja no 977. p. 196-199.

Lehto, E. \& Joki-Tokola, E. 1999a. Kauran ja rehuvirnan seoskasvuston korjuu säilörehuksi. Koetoiminta ja Käytäntö 22.6.1999.

Lehto, E. \& Joki-Tokola, E. 1999b. Virna sopii hyvin rehukasviksi. Koetoiminta ja Käytäntö 21.12.1999.

Leinonen, P. \& Nykänen, A. 2001. Virnat. Luomulehti 20: 8-9.

Lowman, B.G., Scott, N.A. \& Somerville, S.H. 1976. Condition scoring of cattle. The East of Scotland College of Agriculture, Bulletin No.6.

Manninen, M. \& Ojajärvi, P. 2000. Rypsitäydennyksen vaikutus kokoviljasäilörehuruokinnalla hereford- ja ayrshire-hiehojen kasvuun sekä ruhon ja lihan laatuun. Kotieläintieteen päivät 2000. MKL:n julkaisuja no 952. p. $169-172$.

Manninen, M., Virkajärvi, P., Ojajärvi, P., Jauhiainen, L. \& Suvitie, M. 2002. Toisen laidunkauden vaikutus teuraaksi kasvatettavien hf-hiehojen kasvuun sekä ruhon ja lihan laatuun. In: Maataloustieteen päivät 9.10.1.2002. Kotieläintiede. MKL:n julkaisuja no 977. p. 188-191.

Nousiainen, J. \& Hellämäki, M. 1999. NIR-tekniikka kotieläinruokinnan palveluksessa. Lauri Paloheimon 100-vuotisjuhlaseminaari 16.11.1999. Viikin Infokeskus, Helsinki. Suomen nurmiyhdistyksen julkaisu nro 12, p. 26-35.

Nousiainen, J. \& Huhtanen, P. 2000. Säilörehun syönti-indeksi auttaa ruokintastrategian toteuttamisessa. In: Maataloustieteen päivät 2000. Kotieläintiede. MKL:n julkaisuja no 952. p. 15-19.

Rinne, M., Harinen, T., Asikainen, U., Huhta, H. \& Aspila, P. 1998. Ruokinnan voimakkuuden vaikutus teurashiehojen kasvuun. Kotieläintieteen päivät 1998. MKL:n julkaisuja no 924. p. 293-296.

Rinne, M. \& Ojajärvi, P. 1998. Ohra ja rypsirouhe rajoitetusti säilörehua saaneiden teurashiehojen väkirehuna. Kotieläintieteen päivät 1998. MKL:n julkaisuja no 924. p. 297-302.

SAS. 1999. SAS/STAT User's Guide, Version 8, Cary, NC: SAS Institute Inc. 3809 p. 